\title{
SUSTAINABILITY ASSESSMENT FRAMEWORK FOR PROACTIVE SUPPLY CHAIN MANAGEMENT
}

\author{
António Almeida*, INESC Porto, antonio.henrique@fe.up.pt \\ João Bastos, INESC Porto, jsbastos@fe.up.pt \\ Roberto da Piedade Francisco, INESC Porto, roberto.piedade@fe.up.pt \\ Américo Azevedo, INESC Porto, ala@fe.up.pt \\ Paulo Ávila, ISEP, psa@isep.ipp.pt
}

\begin{abstract}
Nowadays, it has been observed an increasing awareness and understanding on the subject of sustainable companies and business models, addressing multi-disciplinary approaches that cover not only economical problems, but also social and environmental challenges. In line with this trend, supply chains and especially Collaborative Networks managers are increasingly aware of these sustainability issues, continuously seeking to meet current human needs while preserving environmental safety. Only this way, focusing on its sustainable growing, it is possible to preserve companies' steadiness.

In order to achieve this overall goal, present decision making related with sustainability policies and practices, becomes a critical issue for the future of each stakeholder in the network. Sustainability networks must ensure that each partner is fully aligned and committed with economic, environmental and social axes that rule the network operational behaviour.

Nevertheless, in order to achieve this level of maturity within such complex and turbulent environments, organizations need to improve the quality of their performance assessment approaches, integrating the different sustainability perspectives. To accomplish this, it is critical to establish specific indicators responsible for materialize and evaluate partners' behaviour, according to wellidentified objectives, as well as fuse this information in a comprehensive and user-friendly way. In line with this concept, this paper presents a new approach, based on a fuzzy logic based algorithm, for sustainable networks performance and risk assessment.
\end{abstract}

\section{Introduction}

In the past decade, Supply Chain Management (SCM) has concentrated the attention from researchers and specialists from the operations management world. The recent past has shown that many companies stressed from the competition, have reduced manufacturing costs as well implemented sustainable practices as much as possible. And yet this effort has proved to be insufficient. This reality is forcing the companies and managers to address the problem of competitiveness and sustainability in a holistic way, by considering the entire supply chain. 
The holistic supply chain management approach is helping the supply chain stakeholders in identifying improvements that can be achieved by planning and managing their supply chain more effectively and also by addressing the sustainability issues in a more proactive way. Moreover, the current reality is showing that the sustainability of supply chains increasingly relies on sustainable supply management practices and policies. A growing number of companies are setting up dedicated sustainable structures, defining the key factors and suitable purchasing policies that affect the selection of suppliers and the formation of the supply networks.

Sustainability is defined as 'development that meets the needs of the present without compromising the ability of future generations to meet their own needs'[1]. According to the UN 2005 World Summit it was noted that sustainability requires the reconciliation of environmental, social and economic demands - the "three pillars" of sustainability.

Particularly within Supply Chains (SC), present decision making related with sustainability policies and practices, is a critical issue for the future of each stakeholder of the network. Sustainability networks must ensure that economic, environmental and social axes are fully aligned within each partner.

Several surveys have shown that while quality and environmental standards such as ISO 9000 [2] and ISO 14001 [3] are commonly implemented and accepted, social standards such as SA 8000 [4] or AA 1000 [5] have hardly been applied so far, and can be regarded as almost irrelevant in many industries [6-8].

The ongoing business development demonstrated that the corporate responsibility does not start and end with each own core business, but extends upstream through the whole supply chain from the raw materials manufacturer up to downstream, the end user [6]. Due to this pressure from supply chain stakeholders to a comprehensive sustainability assessment of the entire network, extended "performance metrics" are required not only on the economic value of a business, but also in its environmental and social impacts.

In the context of SC, the performance metrics evaluation represents an important management challenge due to the heterogeneity present in the networks. Nevertheless, if successfully implemented, performance and risk assessment enables network managers to create enduring value for the multiple stakeholders in the network.

Increasing numbers of organizations report a massive volume of data, with low consistency and high variability in data quality, making it necessary to develop and implement new approaches for SCM sustainable performance assessment. In line with this, organizations need to improve the quality of performance assessment for the sake of both internal and external decision making. Along this trend, the current reality shows that the sustainability issues are here to stay and in supply chain management they are becoming increasingly critical for the success of whole supply chain business. This poses a key challenge for the supply network decision makers.

This paper focuses on this topic, presenting a new approach for performance and risk assessment within supply chain networks, supported in a new and comprehensive Sustainability Assessment Framework (SAF). 
Title

The organization of the paper is as follows: Section 2 presents selected literature on Supply Chain Management, Sustainable Development and Sustainable Supply Chain Management strategies. It also includes relevant references from performance management and risk assessment. A conceptual Sustainability Assessment Framework with its theoretical foundations, architecture and relevant indicators are presented in Section 3. Section 4 includes the methods and tools behind the instantiation of the methodology. And finally Section 5 includes the conclusions and future research directions.

\section{Literature Review}

In this section, it is reviewed the literature available on sustainable supply chain and management in order to identify the challenges and the shortcomings the network stakeholders are facing in assessing and evaluating the current management practices, policies and decision support systems.

\subsection{Supply Chain Management}

According to Council of Supply Chain Management Professionals (CSCMP) supply chain management is an integrating function with primary responsibility for linking major business functions and business processes within and across companies into a cohesive and high performing business model. It includes all of the logistics management activities, as well as manufacturing operations, and it drives coordination of processes and activities with and across marketing, sales, product design, finance and information technology. In this definition, the supply chain is seen as a complex network of suppliers, manufacturers, and distributors delivering goods to end consumers, and their management encompasses the planning and management of all activities involved in sourcing and procurement, manufacturing, and all logistics management activities. It also includes coordination and collaboration with channel partners, which can be suppliers, intermediaries, third-party service providers, and customers [9].

On the last decade aroused a growing need for integrating environmentally sound choices into supply-chain management research and practice. Scrutiny of the research literature have shown that a broad number of references start by presenting a new concept, the green supply chain management (GrSCM) [1012]. Srivastava for instance defined green supply chain management as management practices addressing the influence and relationships between supply-chain management and the environment issues. These include product design, material sourcing and selection, manufacturing processes, delivery of the final product to the consumers as well as end-of-life management of the product after its useful life' [13].

This refocusing of supply chains management practices into environmental issues brought to the forefront the topic of sustainable development from the individual company scope to the level of the entire supply networks. 


\subsection{Sustainable Development}

Making the concept of sustainable development operational for Supply Chains bring up important challenges in terms of measurement and assessment. Without indicators or a quantitative framework, supply chain decision makers seeking sustainable development policies inside the network lack a solid foundation on which to proceed.

As stated previously, the concept of sustainable development includes three dimensions: economic, environmental and social. Yet according to OECD [14], between these three dimensions there are complex synergies and trade-offs among them (see Figure 3).

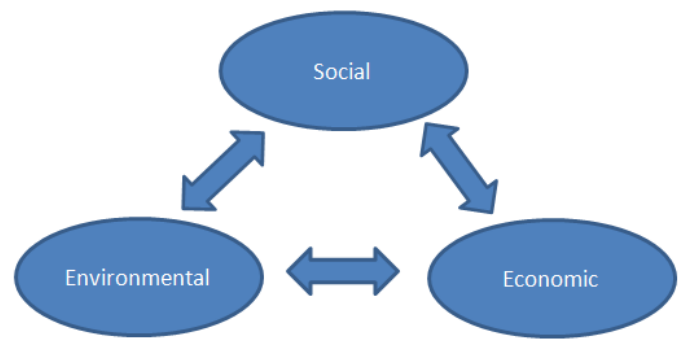

Fig. 1 - Key dimensions of sustainable development [14]

Included in these synergies and trade-offs among the SC surroundings it is possible to identify the following effects:

1. Effects of economic activity on the environment such as resource consumption, waste volumes and pollutants discharge.

2. Effects of economic activity on society such as economic growth, income levels, employment and support for social services.

3. Environmental services to the economy such as provision of natural resources, sanitary landfills, contributions to economic efficiency and employment, human resources technological training.

4. Environmental services to society such as access to resources and facilities, contributions to health, quality working and living conditions.

5. Effects of social aspects on the environment such as environmental education, demographic changes, consumption patterns and environmental awareness.

6. Effects of social aspects on the economy such as labour force, population and residential structures, education and training skills.

To proceed towards sustainable development, companies and specially SC seek to follow policies aimed to increase economic efficiency and material wealth usage in order to take into account social and environmental objectives. Clear in this concept is a focus on inter-generational equity, implying that future generations should have same opportunities to those now available. 
The concept of sustainable production emerged in 1992 at the United Nations Conference on Environment and Development (UNCED) and is closely linked to the concept of sustainable development. According to the Lowell Center for Sustainable Production (LCSP), the concept of sustainable production based on "the creation of goods and services using processes and systems that are non-polluting; conserving of energy and natural resources; economically viable; safe and healthful for employees, communities and consumers; and socially and creatively rewarding for all working people"[15].

This definition of sustainable production not only is consistent with current understanding of sustainable development, since it emphasizes environmental, social and economic aspects of firms' activities, but it also emphasize the operational perspective, since it highlights six main perspectives for a sustainable production: energy and material use (resources); natural environment (sinks); social justice and community development; economic performance; workers, and products.

In fact, when planning a manufacturing system, from the first stage, it is critical to explore a concurrent engineering approach, where facilities and technologies, processes as well as products characteristics should be designed in parallel. That is the reason why, when dealing with sustainability assessment, the complexity increases greatly. Thus, it is essential to explore new methodologies and tools capable to standardize and enhance the way that it could be possible to evaluate the level of sustainable production of a complex manufacturing system, such as a Supply Chain.

\subsection{Sustainable Supply Chain Strategies}

As Morash [16] proposed in his model for supply chain strategy, the business strategy precedes and conditions the supply chain strategy in their objective for operational positioning. And as Perez-Franco [17] demonstrated in his study, in the vast majority of the cases, the business strategy is explicitly stated, and yet the managers have difficulties in translating it to coherent and aligned supply chain practices and policies. Cohen and Roussel [18], in their work identified five critical configuration components for the supply chain management strategy that contribute to alignment with the business strategy: operations strategy; outsourcing strategy; channel strategy; customer service strategy; asset (logistic) network. As is recognized, all of these areas have a critical impact in the sustainability performance of the supply chain.

From the perspective of sustainability, the research literature identifies basically two distinct strategies for sustainable supply chain management practices: supplier management for risks and performance assessment; and supply chain management for sustainable products (mainly in the green/environmental aspects) [19].

From the perspective of planning and supporting the implementation of sustainable supply chain management strategies, the Supply Chain Operations Reference (SCOR) Model (fig. 2), which was developed by the experts and practitioners of the Supply Chain Council, is a major framework for supply chain planning that features supply chain management practices and business process 
reengineering. With version 10.0 of SCOR, the model includes process elements addressing environmental aspects of managing a supply chain called GreenScor. These additions allow the SCOR model to be used as a green supply chain management tool, allowing managers to design and optimize supply chain operations with sustainability in mind [20].

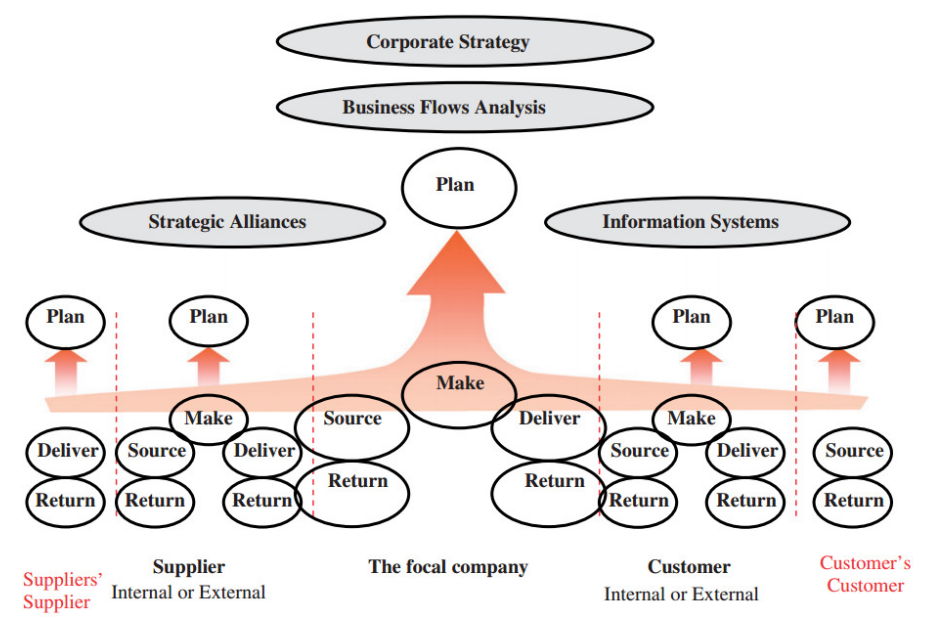

Fig. 2 - Overall view of the SCOR model

\subsection{Performance Management}

According to Sobotka and Platts [21], it is not possible to manage a process if it isn't possible to measure its performance. In other words, performance management should be seen as an essential principle of management, because it not only enables the detection of gaps and bottlenecks in the processes (matching between current performances and desired performance), but also indicates where processes should be improved, namely in the sustainability issues, in order to fulfil these gaps and increase the overall performance of the factory or the entire supply chain. Hence, for sustainable companies, it is critical to determinate and select the key metrics, which, delivered to the right decision maker, can provide the crucial information to assure the factory processes improvement.

In fact, to achieve a useful performance management, it is required to the managers perform an exercise of balance between the interests of the supplychain participants, knowledge about costumer's requirements, environmental factors and the business processes knowledge. Indeed, the choice of performance measures (economical, environmental and social) not only must integrate strategies, resources and processes but also should allow the its continuous improvement. In fact, this choice enhances the company to become more flexible and capable to adapt in real time to the continuously changing market and social demands $[8,22]$.

In order to execute a performance analysis of a complex system, a preliminary step requires the structuring of the raw data available on the 
Title

company. As result of this process performance indicators are generated. However, not all performance indicators are relevant to the system behaviour analysis. It is necessary from the managers to define which are the key indicators to use according to their importance for the process [23]. The key performance indicators (KPIs) are the input information to be analysed once captured by a performance measurement systems on the processes' output. The results obtained from this evaluation intends to be able to provide reliable information for decision making referring the necessary actions to problem solving, continuous improvement, process reengineering, or process innovation. In fact, the KPIs should be selected in order to support decision-makers improve the performance of processes in focus [24]. A linked concept is the key results indicator (KRI); which represent how actions are done in a perspective of a critical success factor. Other related concepts are the results indicator (Rls), or outcomes, that tell us what has been done; and the performance indicators (PIs), that tell us what has to be done. So, according to Parmenter [24], the KPIs "represent a set of measures focusing on those aspects of organizational performance that are the most critical for the current and future success of the organization".

\subsection{Risk Assessment}

The risk assessment stage is one of the critical activities that should be performed during the entire risk management process (Fig. 3). The risk assessment activity aims at identifying what can happen and why (risk identification), which are the consequences, the probability of occurrence (risk analysis), and which are the factors that can reduce the impact and probability of risks occurring (risk evaluation). Therefore, it is advisable to execute this activity following a structured methodology that identifies how the objectives may be affected, and analyses the risk in term of consequences and their probabilities before deciding whether further treatment is required.

One of the most important contributions of the risk assessment goes towards incident prevention instead of post-incident investigation. Risk assessment programs should allow organizations to be more proactive and less reactive during the entire production system life cycle [25]. A proactive risk assessment program should be able to influence organizations to design and evaluate processes before those processes begin [26]. The timing of safety analysis and consequent corrective action is critical to minimize the impact on cost and schedule. 
Author

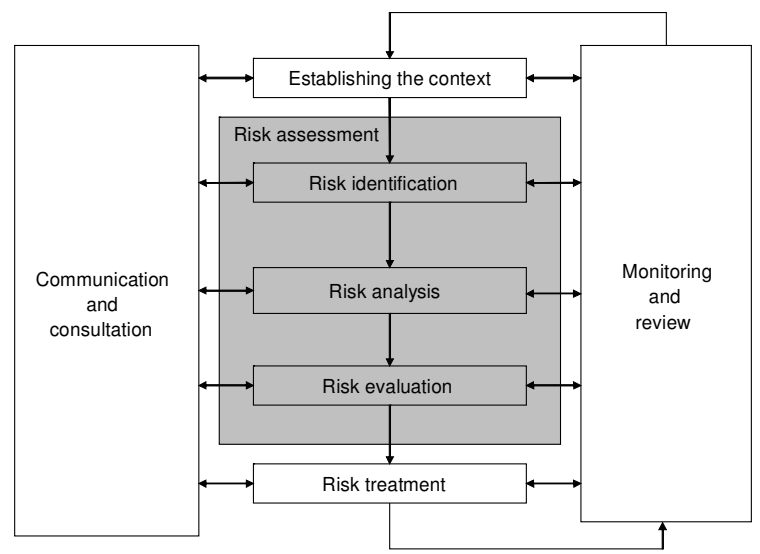

Fig. 3 -Risk Management Process (ISO 31000)

Within the literature review, two main approaches to perform risk assessment can be identified: a qualitative risk analysis and quantitative risk analysis [26].

Qualitative risk analysis methods determine loss based on the knowledge and assessment of a risk analyst (the resulting level of risk may be seen as a combination of consequence and probability, according qualitative criteria). Qualitative methods assume that a loss cannot be expressed as a discrete event. These methods, therefore, try to express the risk in terms of descriptive variables (assessment of a Likert scale from 1 to 5, for example) based on the knowledge and assessment of an analyst [27]. They include Delphi techniques, scenario analysis, fuzzy metrics, comparison risk ranking, and questionnaires.

Quantitative risk assessment measures the risk in specific units, based on practical values for consequences and their probabilities. The risk analysis based on the system modelling approach has its origins in the system dynamics discipline and is normally performed by building a mathematical model of the system. The aim is to predict results for important performance measures. With this type of information it is possible to rank risk events by their potential impact on performance behaviours in a certain time space and depending on the manufacturing system's life cycle stage. Definitely, dynamic approaches employing the physical modelling of the system are required mainly when the deterministic and stochastic behaviours of the system are strongly coupled.

It is important to underline that full quantitative approaches may not always be possible or desirable due to insufficient information on the system, lack of data, influence of human and others factors. Indeed, a comparative semiquantitative or qualitative ranking of risks created by experts should still be effective. By applying a risk assessment based not only on a hazard analysis but also using the system modelling it is possible to make a detailed follow-on action plan composed of additional analyses, corrective/preventive actions and simulations, selection of pertinent criteria, requirements and/or specifications, as well as definition of safety factors for trade-off considerations. 
Title

\subsection{Literature Review Summary}

In view of the physically distributed supply networks environment, supply management is a critical aspect for organizational competitiveness and even more when considering the sustainability aspects, realizing the importance of sustainable supply chain management practices and policies.

Research has identified two main strategies for sustainable supply chain management. The first one labelled supplier management for risks and performance dealing specially with the loss of reputation aspects and related problems. The second strategy is called supply chain management for sustainable products and is focused in the definition of lifecycle based standards for the environmental and social performance of products.

Besides the existence of several reference frameworks for supply chain management, a major gap identified in the literature review is the lack of a comprehensive assessment framework addressing the sustainability dimensions of the supply networks and presenting methods and tools to deal with the overall performance evaluation and risk assessment.

\section{Sustainability Assessment Framework}

This section presents the proposed sustainability assessment framework by revealing the projected architecture and the listing of the main sustainability indicators and dimensions.

From the literature review, it is clear that, risk assessment should be seen as a system modelling approach, where both quantitative and qualitative techniques should be combined. Following a risk assessment based not only on a hazard analysis but also using the system modelling approach, it is possible to make a detailed follow-on action plan composed by additional analysis, corrective/preventive actions and simulations, selection of pertinent criteria, requirements and/or specifications as well as definition of safety factors for tradeoff considerations.

In line with this vision, the sustainability analysis can be seen as a special tool for risk assessment in medium and long terms. In fact, one of the main achievements of this type of risk assessment is based on the identification of driven factors that can provide information about the sustainable growth of a complex manufacturing system.

Therefore, during this section it will be explored a sustainability index for supply chains assessment. In reality, this tool is expected to support decision makers selecting the best topology and strategy, envisioning the decreasing of the risk associated to a SC establishment.

Figure 4 presents the overall step definition of the proposed sustainability analysis embed in the framework. 
Author

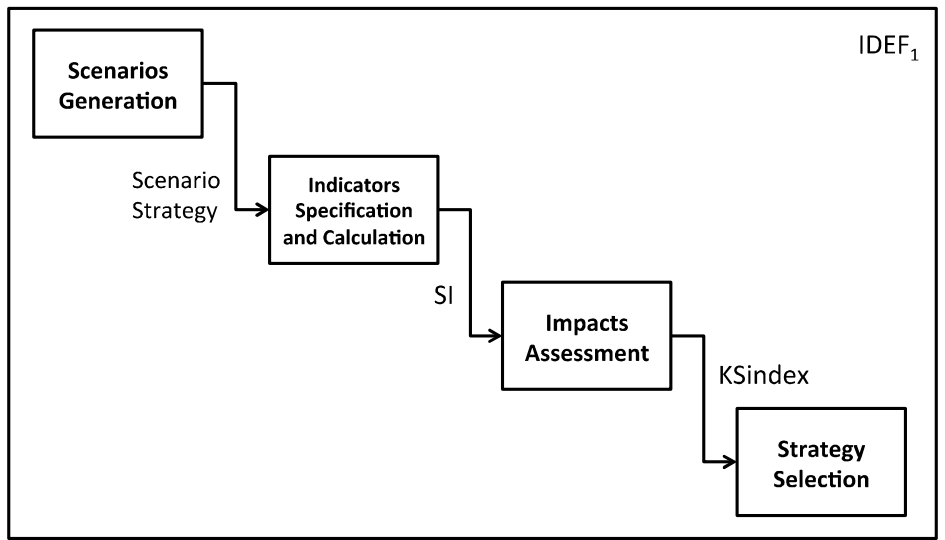

Fig. 4 - IDEF1 Step definition of sustainability analysis

\subsection{Architecture}

In order to achieve a reliable performance management framework, oriented to the sustainably issues, it is necessary to clearly define the meaning of the concept sustainable development. Based on this premise, it should be specified the right indicators that, aligned with the organization's vision and the technological infrastructures, make it possible to extract the raw data from the shop floor, combine this huge quantity of data in a structured set of Sustainable Indicators (SI) and provide insights about the supply chain growth behaviour.

It could be argued that, it is not possible to have a set of sustainable indicators, applicable to any company or organization, since each manufacturing system should present its own characteristics, depending not only on the business activities and market but also on the strategy and vision of their stakeholders. However, the key pillar of this work is based on the idea that in order to implement a performance management strategy for sustainability issues, it is critical to have a well defined data model, capable to structure a series of standard SIs. Nevertheless, this data model should always be extended in order to follow the specifications of each manufacturing system.

The problem is, if it is desired to compare different SC's topologies, how many and which indicators to use? Moreover, it is clear that decision makers are not capable to use every Sustainable Indicators that may potentially be available, raising an important issue related with data simplification that, at the same time, maximize the information within an unique but relevant variable.

In order to answer to the questions raised before, a sustainability framework was developed (Fig. 5). Frameworks can be seen as important tools to structure work on indicators and on underlying performance. Because sustainable development encompasses three different dimensions and their interactions, there is a vast range of relevant indicators requiring a reference model in order to be framed in an organised structure. In line with this, the first stage of the sustainability framework definition is based on the necessity of harmonize an exhaustive list of potential Sls, as well as a data model for structuring these indicators. Since the sustainability concept should be flexible enough to adapted 
to each system's characteristics, it will be explained how a system thinking approach can be used in the identification and characterization of the main feedback loops presented into a complex manufacturing system.

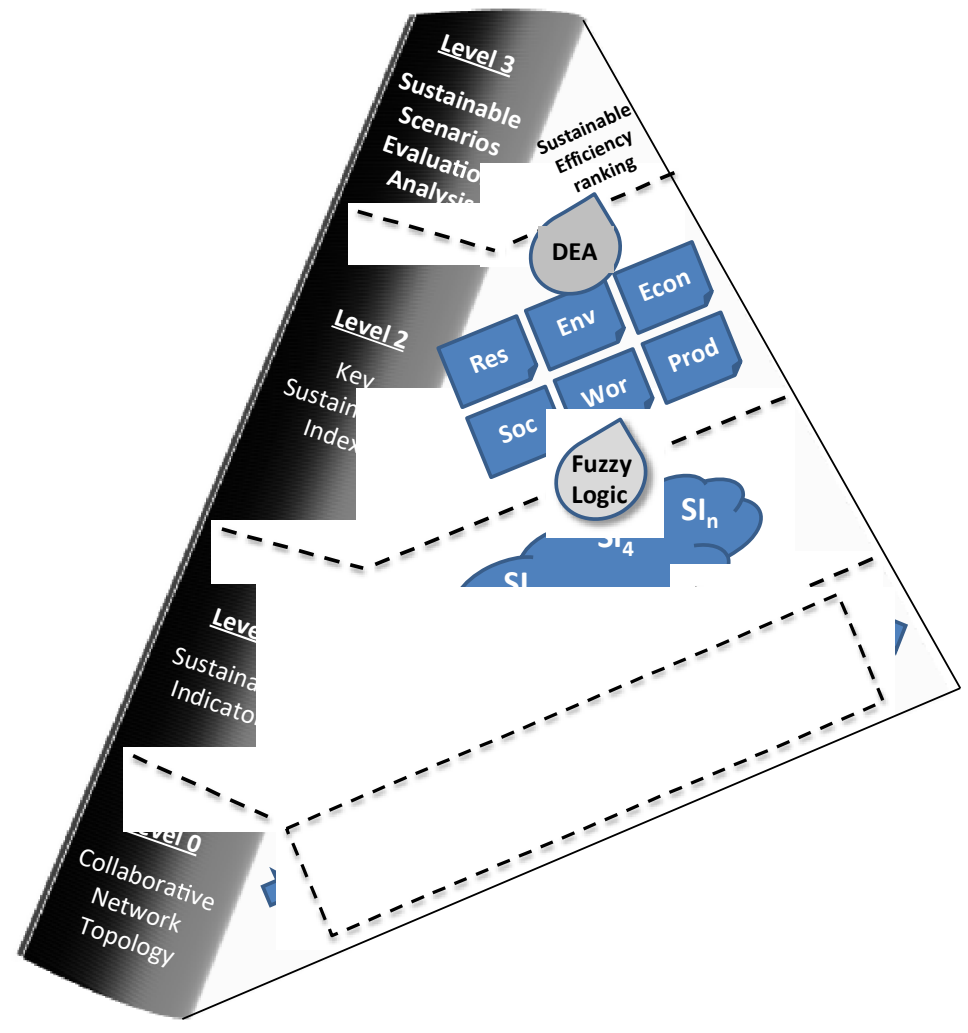

Fig. 5 -Sustainability Framework Pyramid

Aiming to optimize the quantity of information available to decision makers, the second layer of the sustainability framework (see figure 5) is responsible to compile the information available into a sustainability index for each perspective of the sustainable production concept. This way, it becomes possible to evaluate the impact of a specific supply chain topology into a social, environmental and economic dimension, based not only on the measures obtained for each Sls, but also taking into account the systems dynamics and stakeholder's visions. In order to handle with the subjectivities imposed by this type of performance assessment, a Fuzzy Logic approach was adopted.

Finally, level 3 of the sustainable pyramid is responsible by the comparison and selection of the best SN's topology, based on a sustainable efficiency concept. Based on SCOR-Model approach, a supply chain life cycle is composed by four main stages: Source, Make, Deliver and Return. For each of these stages, stakeholders have to take decisions that will affect negatively or positively the achievement of strategic goals in medium or long terms. Therefore, it becomes critical to analyse which solutions present a better ratio between profits and social, economic and environmental impacts. 
Author

For this important layer of the sustainable framework, a Data Envelopment Analysis (DEA) technique was selected. The DEA is based on a linear programming approach that evaluates relative efficiencies of a specific SC topology in comparison to others solutions.

\subsection{Sustainable Indicators}

In simple terms, a sustainable development is the realistically attainable growth that a manufacturing system should keep in order to maintain the risk in a controllable range, without achieve a no-return point. Indeed, a business that grows too fast may find it difficult to fund this growth while, a business that grows too slowly, may stagnate and cease to be competitive. Therefore, one of the main challenges becomes finding the optimum Sustainable Rate. This is the maximum growth rate that a company can sustain without having to increase financial leverage or without affecting the environmental and social dimensions.

Traditionally financial and quality indicators have been used to benchmark performance (e.g. return on investment, market share). However, these are mainly lagging indicators, exposing the results of a certain strategy. With the increasing of competition between companies, it became critical dealing with leading indicators, capable to provide insights about the future. Exploring a proactive performance management approach, it is possible to take decision based on information that anticipates future performance behaviours, instead of analysing information mainly linked to past behaviours. Kaplan and Norton called them as "Performance Drivers"[28].

The growth of the sustainable thinking is a fact that proves this changing of paradigm. Companies are realizing the importance of improving environmental and social performances in order to save money, enhance products quality, improve company's image, as well as stimulate optimized operational performances, in order to building a competitive advantage.

In line with this, it can be identified the need to develop and implement sustainable indicators as production oriented variables, linked to the three dimensions of the sustainable development: environmental, social and economic perspectives. Through the specification of this kind of indicators it is expected to address all key aspects of production, capable to provide insights about the sustainable development of the manufacturing systems: energy and material use (resources perspective), natural environment (sinks perspective), community development and social justice (Social perspective), economic performance, employees (workers perspective), and products.

Despite the fact that each manufacturing systems presents its own characteristics and specifications, this papers is based on the idea that it is possible to have a standard set of indicators, which can be applied to any manufacturing system covering the dimensions enumerated before. Therefore, in Table 1 it is possible to visualize a series of sustainable indicators divided by sustainable production dimensions. For each indicator, it is provided the strategic goal, which is expected to be evaluated, as well as the respective unit of calculation. Due to their coverage, each indicator could be applied to any 
manufacturing system that requires assessing if the strategy adopted is fulfilling the sustainability issues, and thus, exploring its impact on the future.

Table 1 - Sustainable Indicators (partially sourced from [20])

\begin{tabular}{|c|c|c|c|}
\hline $\begin{array}{l}\text { Sustainability } \\
\text { Perspectives }\end{array}$ & Strategic Goal & Indicator & Unit \\
\hline \multirow{6}{*}{$\begin{array}{c}\text { Energy \& } \\
\text { Material Use }\end{array}$} & $\begin{array}{c}\text { Increase the reuse of energy (e.g } \\
\text { thermal energy) }\end{array}$ & Percent of energy reused & $\%$ \\
\hline & $\begin{array}{l}\text { Reduce the cost of energy inputs for } \\
\text { warehouse operations as a \% of total } \\
\text { storage costs }\end{array}$ & Warehouse energy costs & $\%$ \\
\hline & $\begin{array}{l}\text { Reduce Energy inputs for the Make } \\
\text { process per unit produced. }\end{array}$ & Energy Consumption per Unit & $\%$ \\
\hline & Reduce the use of fresh water & Fresh water consumption & Liters \\
\hline & Reduce Material Use & $\begin{array}{l}\text { Materials used (total and per } \\
\text { unit of product family) }\end{array}$ & $\mathrm{Kg}$ \\
\hline & $\begin{array}{l}\text { Increase the use of energy from } \\
\text { renewable sources }\end{array}$ & $\begin{array}{l}\text { Percent of energy from } \\
\text { renewables }\end{array}$ & $\%$ \\
\hline \multirow{7}{*}{$\begin{array}{l}\text { Natural Environment } \\
\text { (including Human } \\
\text { health) }\end{array}$} & $\begin{array}{l}\text { Increase number of suppliers used that } \\
\text { have a validated Environmental } \\
\text { Management System or ISO } 14000 \\
\text { certification }\end{array}$ & $\begin{array}{c}\text { Suppliers with an EMS or ISO } \\
14001 \text { ?certification }\end{array}$ & $\%$ \\
\hline & $\begin{array}{c}\text { Reduce the \% of material (by weight) } \\
\text { issued for production that is classified } \\
\text { as hazardous material }\end{array}$ & $\begin{array}{c}\text { Hazardous materials used } \\
\text { during production process as } \\
\text { [a \% of all materials }\end{array}$ & $\%$ \\
\hline & $\begin{array}{l}\text { Reduce the annual weight of waste } \\
\text { generated from warehousing processes }\end{array}$ & Warehousing solid waste & $\mathrm{Kg}$ \\
\hline & $\begin{array}{l}\text { Reduce the amount of waste generated } \\
\text { before recycling (air, water and land) }\end{array}$ & $\begin{array}{l}\text { Kilograms of waste generated } \\
\text { before recycling (emissions, } \\
\text { solid and liquid waste) }\end{array}$ & $\mathrm{Kg}$ \\
\hline & Reduce greenhouse gas emissions & Global warming potential & $\begin{array}{l}\text { Tons } \\
\mathrm{CO}_{2}\end{array}$ \\
\hline & Increase pollution Prevention Ratio & $\begin{array}{l}\text { Compliance costs directed to } \\
\text { pollution prevention activities } \\
\text { as a percent of total } \\
\text { compliance costs. }\end{array}$ & $€ / \$$ \\
\hline & $\begin{array}{l}\text { Decrease number of reportable air, } \\
\text { water, or solid waste accidental } \\
\text { releases per year }\end{array}$ & $\begin{array}{l}\text { Reportable Release Incidents } \\
\text { with environmental impact }\end{array}$ & \# \\
\hline \multirow{3}{*}{$\begin{array}{l}\text { Economic } \\
\text { Performance }\end{array}$} & $\begin{array}{l}\text { Decrease average time associated with } \\
\text { aligning the supply chain unit plan with } \\
\text { the financial plan }\end{array}$ & $\begin{array}{l}\text { Align Supply Chain Unit Plan } \\
\text { with Financial Plan Cycle Time }\end{array}$ & hours \\
\hline & $\begin{array}{l}\text { Decrease value at Risk (VaR) - the sum } \\
\text { of the probability of risk events times } \\
\text { the monetary impact of the events for } \\
\text { the specific product or customer. }\end{array}$ & $\begin{array}{l}\text { VaR of product/ customer } \\
\text { performance }\end{array}$ & \\
\hline & $\begin{array}{l}\text { Increase the percent of mitigation plans } \\
\text { implemented for specific supplier or } \\
\text { supplier base to mitigate risk. }\end{array}$ & $\begin{array}{l}\text { Supplier Mitigation Plans } \\
\text { Implemented }\end{array}$ & $\%$ \\
\hline
\end{tabular}




\begin{tabular}{|c|c|c|c|}
\hline & $\begin{array}{l}\text { Decrease average time associated with } \\
\text { managing WIP inventory }\end{array}$ & $\begin{array}{c}\text { Manage In- Process Products } \\
\text { [(WIP) Cycle Time }\end{array}$ & hours \\
\hline & Reduce EHS compliance Costs & $\begin{array}{l}\text { Cost associated with EHS } \\
\text { compliance (e.g. fines, } \\
\text { liabilities, worker } \\
\text { compensation, remediation, } \\
\text { etc.) }\end{array}$ & $€ / \$$ \\
\hline & $\begin{array}{l}\text { Achieve zero costumer complaints or } \\
\text { returns }\end{array}$ & $\begin{array}{l}\text { Rate of costumer complaints or } \\
\text { returns }\end{array}$ & $\%$ \\
\hline & $\begin{array}{l}\text { Increase Stakeholders involvement in } \\
\text { decision making process }\end{array}$ & $\begin{array}{l}\text { Openness to stakeholders } \\
\text { review and participation in } \\
\text { decision making process }\end{array}$ & $\#$ \\
\hline \multirow{4}{*}{$\begin{array}{l}\text { Community } \\
\text { Development and } \\
\text { Social Justice }\end{array}$} & $\begin{array}{l}\text { Increase Community spending and } \\
\text { charitable contributions }\end{array}$ & $\begin{array}{l}\text { Increase Community spending } \\
\text { and charitable contributions as } \\
\text { percent of revenue }\end{array}$ & $\%$ \\
\hline & $\begin{array}{l}\text { Increase employment for local } \\
\text { community }\end{array}$ & $\begin{array}{c}\text { № employees per unit of } \\
\text { product/sales }\end{array}$ & $\#$ \\
\hline & $\begin{array}{l}\text { Increase community-company } \\
\text { partnerships }\end{array}$ & $\begin{array}{l}\text { Number of community- } \\
\text { company partnerships }\end{array}$ & $\#$ \\
\hline & $\begin{array}{c}\text { The number of environmental violations } \\
\text { per year that are a result of personnel } \\
\text { error or improper training }\end{array}$ & $\begin{array}{c}\text { \# of staff-related } \\
\text { environmental violations }\end{array}$ & $\#$ \\
\hline \multirow{6}{*}{ Workers } & $\begin{array}{l}\text { Achieve zero lost workdays as result of } \\
\text { work related injuries and illness }\end{array}$ & $\begin{array}{l}\text { Lost workdays injuries and } \\
\text { illness case rate }\end{array}$ & Rate \\
\hline & $\begin{array}{l}\text { Increase the rate of employee } \\
\text { suggested improvements in quality, } \\
\text { social and EHS performance }\end{array}$ & $\begin{array}{l}\text { Rate of employee's suggested } \\
\text { improvements in quality, social } \\
\text { and EHS performance }\end{array}$ & $\#$ \\
\hline & Reduce turnover rate & $\begin{array}{l}\text { Turnover rate or average } \\
\text { length of service of employees }\end{array}$ & Rate \\
\hline & Increase employee training & $\begin{array}{l}\text { Average number of hours of } \\
\text { employee training per year }\end{array}$ & Hours \\
\hline & $\begin{array}{l}\text { Increase employee well-being and job } \\
\text { satisfaction }\end{array}$ & $\begin{array}{l}\text { Percent of employees who } \\
\text { report complete job } \\
\text { satisfaction }\end{array}$ & $\%$ \\
\hline & $\begin{array}{l}\text { The number of products that meet } \\
\text { desired environmental performance } \\
\text { specifications as a per cent of total } \\
\text { products produced }\end{array}$ & $\begin{array}{l}\% \text { of products meeting } \\
\text { specified 国environmental } \\
\text { performance requirements }\end{array}$ & $\%$ \\
\hline \multirow{3}{*}{ Products } & $\begin{array}{l}\text { Design all products so that they can be } \\
\text { disassembled, reused or recycling }\end{array}$ & $\begin{array}{l}\text { Percent of products designed } \\
\text { for disassembly, reused or } \\
\text { recycling }\end{array}$ & $\%$ \\
\hline & Use $100 \%$ biodegradable packaging & $\begin{array}{l}\text { Percent of biodegradable } \\
\text { packaging }\end{array}$ & $\%$ \\
\hline & $\begin{array}{l}\text { Increase number of products with take- } \\
\text { back policies }\end{array}$ & $\begin{array}{l}\text { Percent of products with take- } \\
\text { back policies in place }\end{array}$ & $\%$ \\
\hline
\end{tabular}


However, if it is true that, there are a series of issues common to all companies such as energy and water use, work-related injuries and illnesses, among others, it is also a fact that differences between manufacturing systems should be taken into account, in order to be avoided an over-simplicity approach.

In line with this, the simple implementation of a standardized set of sustainability indicators may miss key impacts and causal loops, causing that the performance management mechanism became not capable to cover the entire system dynamics. Thus, if an organization aims to increase their level of maturity in terms of performance management, it is necessary to define supplemental indicators, capable to cover and evaluate production systems specifications.

In order to support companies defining their specific supplemental indicators, as well as promote the idea that using sustainable indicators is not static but rather a continuous and evolutionary process of setting goals and measuring performance, the following chapter will present an approach based on the system thinking concept that can support companies defining the supplemental indicators responsible by assess the specific feedback loops of each manufacturing system.

\section{Methods and Tools}

This section extends the sustainability assessment framework by describing the methods and tools that support the reference model proposed.

\subsection{Systems Modeling}

The performance management concept defines that in order to take the decision that will really improve the manufacturing system and support the organisation in achieving their strategic targets, it is crucial to periodically collect and assess information feedback about the real world. By using this information in a continuous way, it is possible to revise the existing understanding on the system, as well as the strategy adopted to drive the perception of the state of the system closer to the reality. Hence, industrial dynamics emerged with the goal of dealing with what information should be available at a decision point, as well as the consequences of defects and gaps in the information taken into account. Only this way can organisations provide decision-makers with the right information that will allow them to approximate their vision of the system to reality, and thus develop proactive management behaviour.

Aiming to provide an important contribution in the scope of the industrial dynamics, Jay Forrester at the MIT developed the system dynamics approach as a solution to help decision-makers enhance their knowledge on varying (or dynamic), non-linear, closed boundary systems behaviours and in converting real-life situations into enhanced simulation models [29]. The system dynamics approach was then created as a standard for information flow representation using a complex system based on the policies that govern those systems.

The fundamental concept of this methodology is that manufacturing systems should be represented by a series of stocks and rate variables, embedded within 
a feedback structure. Stock variables represent accumulations within a system, or describe the state of the system. Furthermore, rate variables flow from one area of the system to another and control stock changes. In other words, rate variables model the system's policies imposed by endogenous and exogenous factors in order to represent the system dynamics as reliably as possible. While endogenous variables can be easily managed, since they are strictly connected with the decision taken by systems stakeholders, exogenous factors cannot be controlled due to the fact that they are mainly linked to the external environment that surrounds the system and, directly or indirectly, affects the normal behaviour of the system.

From the knowledge generated by this learning model, it is possible to understand and represent the synergies observed in the real world, and thus understand which will be the impact of current decisions in the future. Based on this knowledge it becomes trivial to identify the series of additional sustainable indicators (leading factors) that should be measured from the operational level and captured from the strategic level in order to cover the entire system's dynamics and thus evaluate the fulfilment of the strategic goals defined.

In sum, the idea of combining performance management with system dynamics is almost natural since these two concepts complement each other. For instance, while performance management intends to improve the systems performance based on feedback analysis, system dynamics support decisionmakers so that they can explore and understand the existing feedback loops and their synergies.

\subsection{Key Sustainable Index}

As previously explained, the sustainable production concept is composed by a series of perspectives such as: social, product design, workers, environment, and others. Thus, when a decision maker needs to take a decision for a specific stage of the SC life cycle, there is a huge quantity of sustainable indicators to be taken into account. Thus, it is now important understand how it is possible to develop a tool capable of merge, for each dimension, the respective Key Sustainability Indicators and calculate a specific Sustainable Index.

One common way of presenting the indicator data is by constructing a "spider diagram," an $\mathrm{n}$-dimensional polygon where $\mathrm{n}$ is the number of indicators. When several alternative options are represented in such a diagram, an easy decision is hard to make from the clutter of the data. Therefore, different authors have been exploring a single aggregated index that provides an easy and unambiguous decision on the competing alternatives for comparative sustainability.

However, due to the subjectivity and non-deterministic nature of most of the sustainability indicators, a modelling difficulty arises when it is necessary to specify and manage the weighting factor for each indicator. Thus, in order to deal with the non-linearity imposed by the subjectivity associated to the sustainability vision of a stakeholder, it is adequate to use a fuzzy logic technology capable of analyse each of the key indicator and retrieve the assessment corresponding to each dimension. 
This fuzzy logic analysis can be performed through the use of the equation represented in figure 6 . In the sustainability index fusion equation for each of the perspectives of a sustainable production it is calculated a Key Sustainable Index. This calculation is performed by a fuzzy function that receives as inputs the real values measured for each of the Sls. But how should be defined the fuzzy function responsible by the sustainable index calculation?

$$
\left[\begin{array}{c}
K S I_{\text {Res }} \\
K S I_{\text {Env }} \\
K_{\text {EI }} \\
K S I_{\text {Soc }} \\
K S I_{\text {Wor }} \\
K S I_{\text {Prod }}
\end{array}\right]=\left[\begin{array}{c}
f_{\text {fuzzy }}\left(S I_{\text {Res }}\right) \\
f_{\text {fuzzy }}\left(S I_{\text {Env }}\right) \\
f_{\text {fuzzy }}\left(S I_{\text {Econ }}\right) \\
f_{\text {fuzzy }}\left(S I_{\text {Soc }}\right) \\
f_{\text {fuzzy }}\left(S I_{\text {Wor }}\right) \\
f_{\text {fuzzy }}\left(S I_{\text {Prod }}\right)
\end{array}\right]
$$

Fig. 6 - Sustainability Index Fusion

Lotfi Zadeh introduced the Fuzzy Logic in 1960, in order to respond to problems with non-probabilistic uncertainties. Since the beginning, fuzzy logic technology has been widely applied to support decision-makers in the classification of complex problems. Fuzzy Logic is the opposite of certainty and precision. Indeed, this technology is normally used when there isn't quantitative detailed knowledge and uncertainty is significant in the system to be analysed. Moreover, fuzzy logic is presented as an interesting tool to model non-linear systems, which are very common in the real world. With this non-linear system model, it is possible to achieve a higher definition, diminish the modulation error and characterize more complex systems. The supporters of this tool argue that everything that cannot be clearly defined is classified as fuzziness, therefore the adequacy of this approach. The Fuzzy system model is divided into four main components, according to Figure 7.

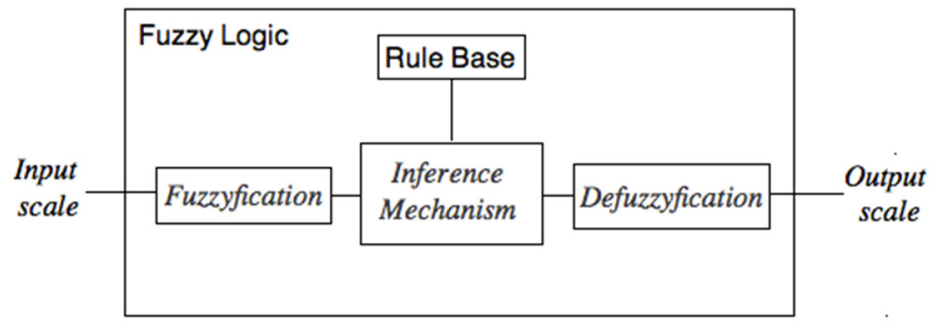

Fig. 7 - Fuzzy Logic Schema

The fuzzyfication process specifies the system's fuzzy inputs mapped in qualitative outputs. Each fuzzy variable is set up by states, which are sets that have a membership function associated. In a simplified way, a membership functions can be seen as a graphical representation of the magnitude of each input's participation. Then, in order to normalize the SI inputs in the image of the network system, it is essential to have relevant knowledge about the impact of each SI on the system that will be modulated in order to setup the fuzzy logic control. 
Indeed, according to the impact of each SI value oscillation, the system manager can tune the membership function in order to represent this impact factor. For example, as depicted in the graph represented in figure 8, the behaviour produced by the B2 curve is much more reactive than the one produced by the B1 curve. This can be easily observed in a real scenario, in any of the sustainable dimensions. Taking the environmental dimension as example, it is well known that the impact of the $\mathrm{CO} 2$ within the environment condition, despite negative, is lesser harmful than methane. Therefore, taking this as knowledge base, the production system manager can tune each of the behaviour curves in order to describe and distinguish the impact caused by a little oscillation in both cases.

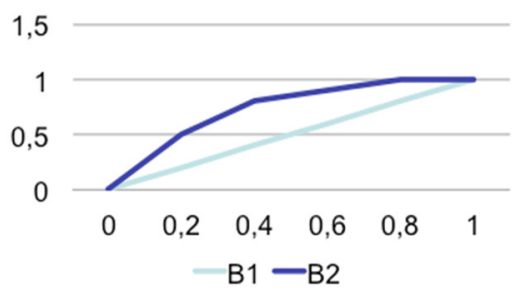

Fig. 8 -SI Impact Behaviour

To compile the knowledge existing about relationship between the different SI for each sustainable dimension, normally represented by output linguistic values, a rule matrix is used (e.g. "if $X$ is very high, and $Y$ is high, then $Z$ is very Low"). When the rules matrix that model the system and support all the combinations possible between the SI are defined, it becomes critical to define the contribution of each rule for the fuzzy system, using for example the Mamdani-type [30, 31]. In the following picture (see figure 9) it is possible to visualize the main steps described previously.

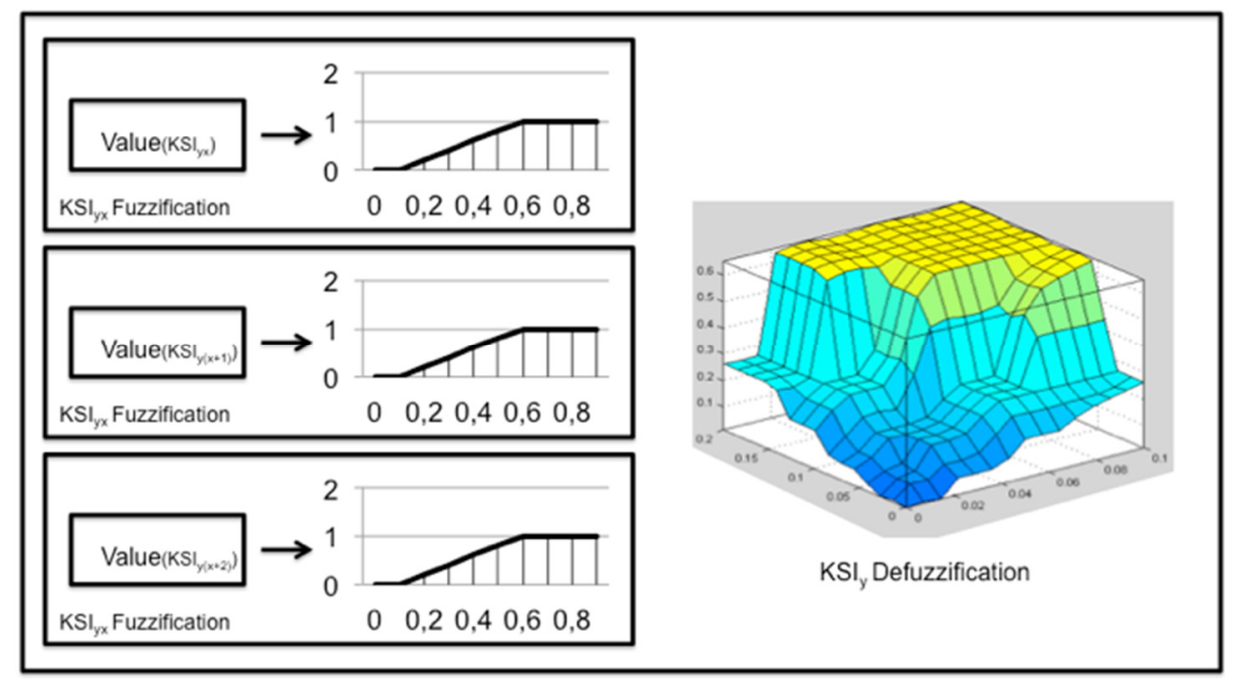

Fig. 9 - Overall Framework 
In order to get the fuzzy result, it is necessary to translate the variable fuzzy states into real and concrete values (defuzzyfication process). In order to perform this operation it is usually applied the centre of gravity method, also known as centroid. This method consists of calculating the fuzzy set mass centre.

At this stage, it is already available the assessment value for each of the sustainable perspectives. However, in order to calculate the overall Sustainability Index, it is necessary to perform a final approximation, where a Data Envelopment Analysis is proposed. It is also important to underline that, all KSI will be used with the same weight for the overall index computation. However, this is only true since, during the fuzzification process, the network manager has the chance to define the membership functions and, consequently the corresponding importance and impact for the overall network sustainability. This way, the subjectivity imposed by this type of performance management is completely absorbed at this stage of the system modelling.

\subsection{Sustainable Scenarios Evaluation Analysis}

The third level of the sustainable framework pyramid is mainly oriented to SCs topology benchmarking. Based on the results obtained from the previous stage of the framework it is expected to select from a list of possible SC topologies the suitable one that, for a specific scope, presents a better sustainable efficiency index.

The sustainable efficiency index is a leading indicator developed based on the necessity to evaluate, in medium and long terms, the impact caused by the strategies adopted on future SC sustainable growth. In other words, with this index it is expected to analyse which SC topology provides a better ratio between profits and non-sustainable impacts on social, economic and environmental dimensions, maximizing the equation following presented.

$$
\begin{aligned}
& \text { maximize } D=\frac{\sum \text { Profits }}{\text { non }- \text { Sustainable Impacts }}
\end{aligned}
$$

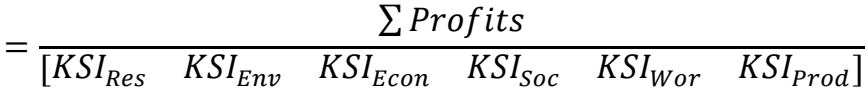

where:

D: Objective function to be maximized

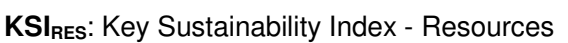

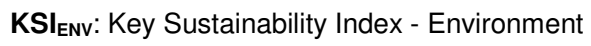

KSI Econ: Key Sustainability Index - Economic

KSI soc: Key Sustainability Index - Social

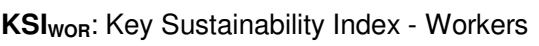

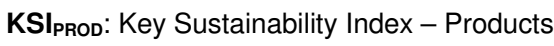

Equation 1 - Sustainable efficiency index 
Author

An efficiency measure compares the ratio output/input of the solution assessed with the maximum value of this ratio observed in others solutions. This notion of efficiency leads to an easy evaluation in the case of analysis involving a single input and a single output. However, in the scope of this research, at this stage of the framework there are available different sustainable indexes, related with each of the sustainable production dimensions.

Therefore, the major objective of this stage of the framework is to use a Data Envelopment Analysis (DEA), originally developed by Charnes et al. [32], as a method for complementing the information provided by the key sustainable indexes, calculated at the previous stage of the pyramid. Indeed, one of the main advantages of this technique is the possibility of aggregating the multiple dimensions of sustainable production concept, evaluated by several KSIs, into a single summary measure of performance. This enables obtaining a ranking that reflects relative performance among the SCs topologies possible.

DEA is a technique for comparing the efficiency of a relatively homogeneous set of organizational decision making units (DMUs). Moreover, this technique is normally used to evaluate organisational units that use multiple resources to produce multiple outputs (products). However, in this specific case where it is expected to assess the sustainable development of a Supply Chain, a DMU will be a possible SC topology, which sustainable efficiency will be calculated and compared with the others SC topologies. In addition, resources concept will be represented by the non-sustainable impacts, formalized by the key sustainable indexes, while the revenues and profits of the Supply Chain will represent the outputs of the SC (fig 10).

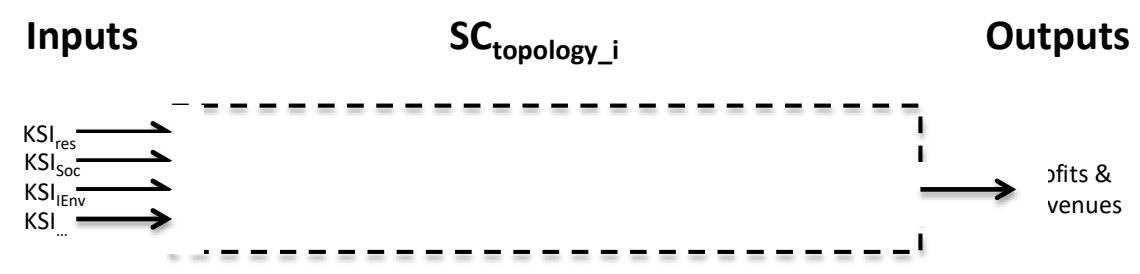

Fig. 10 -Supply Chain topology

In these circumstances, to be able to compute the sustainable efficiency index, it is required an aggregation of the multiple $\mathrm{KSI}$ and outputs in a single performance ratio corresponding to the weighted sum of outputs divided by the weighted sum of inputs (Eq. 2). The main difficulty associated with the estimation of efficiency in these cases involves the selection of appropriate weights. The DEA model determines the weights that give the highest possible relative efficiency score for each SC topology, keeping the efficiency scores of all other SCs topologies less than or equal to unity when evaluated with similar weights. If the unit assessed does not obtain the maximum efficiency score $(100 \%)$, this shows that its peers are more efficient even when all the weights are set to maximise the score of the focus unit.

$$
\text { maximize } h_{0}=\frac{\sum_{r=1}^{t} u_{r} * y_{r j o}}{\sum_{i=1}^{m} v_{i} * x_{i j o}}
$$


Title

$$
\begin{gathered}
\frac{\sum_{r=1}^{t} u_{r} y_{r j}}{\sum_{i=1}^{m} v_{i} x_{i j}} \leq 1, \quad j=1 \ldots n \\
u_{r}>\varepsilon, \quad r=1 \ldots t \quad v_{i}>\varepsilon, \quad i=1 \ldots m
\end{gathered}
$$

Equation 2 - Performance ratio

As output, the framework derives a single summary measure of sustainable efficiency for each SC topology, which is calculated based on the comparison with the others possible SC topologies. Therefore, the DEA tool is capable to identify a subset of efficient SC topologies. It is important to underline that this subset will be composed by a series of topologies that present an efficient behaviour in different scopes. This means that when assessing different topologies it is necessary to take into account the size and objectives for which the SC will be created. Thus, this tool will also support decision determining the right balance between input and output targets, corresponding to a certain efficient operation.

\subsection{Summary and Discussion}

In sum, a performance management framework oriented to sustainability was developed based on four main stages. Initially, a collaborative network topology should be identified and designed. At this stage it is critically to not only understand the global strategy of the network but also clear identify which are the partners performing at this network as well as their roles and expectations. Following, a series of sustainable indicators should be designed in order to extract in a structured way the correct information related with the sustainable development, in terms of six main dimensions: energy and material use, natural environment, community development and social justice, economic performance, employees, and products. For each of these dimensions, a key sustainable index should be calculated based on a fuzzy approach that calculate each of these metric taking into account the different roles and perspectives of the stakeholders involved into the collaborative network. It is important to underline that this is a critical step, since it is expected to go from a series of indicators to a more aggregated set of information where the complexity of a certain supply chain should be taken into account.

Finally, the efficiency of a specific network should be calculated in terms of sustainability. This can be an important feature for world-class organizations since it will allow decision makers to compare their strategies with their competition and perform some benchmarking. In case that a network is not considered to be the leader in terms of sustainable efficiency, then decision makers are able to identify in which of the six perspectives it is feasible to improve in order to enhance their overall sustainable efficiency.

\section{Conclusions}

At the core of sustainable development is the need to consider "three dimensions": social, economical and environmental. No matter the context, the basic idea remains the same, people, habitats and economic systems are inter- 
Author

related. It is common to ignore this interdependence for short periods of time, but history has shown that before long, mankind is reminded of it by some type of alarm or crisis.

Especially on networked organizations such as supply chain enterprises, the sustainability issues arises as relevant in performance evaluation and risk assessment for the survival of the network.

Sustainability systems are complex in nature. Beyond the idea of removing undesirable environmental impacts from processes, products, or infrastructure, these systems also need to be analyzed from the viewpoints of economic and societal impacts. Scientific sustainability is best understood in comparative terms, and the determination of comparative sustainability requires the use of indicators or metrics that represent the three pillars of sustainability. Balancing the impacts in these dimensions of an anthropogenic activity requires careful selection of indicators that capture the totality of the system. Often, however, not all impacts will be relatively favourable, and a large number of indicators make the task difficult for decision-making. Making decisions and communicating these decisions would be considerably easier if we can collapse the values of these indicators into a single index that represents the totality of the system.

In line with this, the current work presents the main concept and vision of a set of key sustainability indicators as means to evaluate the longer-term implications of current decisions and behaviours in supply chains. These can be seen as special key performance indicators that should be capable of expressing the behaviour of a network in the three described dimensions: Environment, Social and Economical. In order to compile all the data referent to each of the sustainable perspectives, this paper presents a framework that supports not only the KSI selection, but also the Sustainable Development index calculation. Indeed, with this information, it is possible to introduce a useful measure and assessment method capable of support decision makers evaluating if the SC is achieving sustainable development. Moreover, this framework is capable of providing a benchmark mechanism, to help managers comparing and assessing different networks in a coherent way.

As future work, it will be expectable to design and setup a simple but reliable pilot case, based on a real industrial scenario, where it will be possible to test and validate the framework here presented. Therefore, selected the supply chain which will be used for this pilot case, a performance measurement system will be designed based on a series of sustainable indicators. Following different scenarios for this supply chain will be created in order to have different instances of the same SC but with different values for each of the key sustainable indexes. Finally, the DEA algorithm will be applied aiming to verify if the different instances will be ranked in a correct way, as well as the relationships between the most and less efficient supply chains, in terms of sustainable growth. 


\section{References}

1. Dee, J., Sustainable Growth, in Small Business, Big Opportunity, ed. J. Bowen. 2010, Melbourne: Sensis Pty Ltd.

2. ISO, ISO 9001:2008 - Quality Management Systems. 1987, International Standards Organization.

3. ISO, ISO 14001:2004 - Environmental Management Systems. 1992, International Standards Organization.

4. SAI, SA8000 - Social Certification. 2014, Social Accountability International.

5. Accountability, AA1000 AccountAbility Principles Standard. 2008, Accountability.

6. Beske, P., J. Koplin, and S. Seuring, The use of environmental and social standards by German first-tier suppliers of the Volkswagen AG. Corporate Social Responsibility and Environmental Management, 2008. 15(2): p. 63-75.

7. Kolk, A., A decade of sustainability reporting: developments and significance. International Journal of Environment and Sustainable Development, 2004. 3(1): p. 51-64.

8. Böhringer, C. and P.E. Jochem, Measuring the immeasurable-A survey of sustainability indices. Ecological Economics, 2007. 63(1): p. 1-8.

9. (CSCMP), C.o.S.C.M.P. Supply Chain Management Definitions. 2013 [cited 2013 08-05-2013]; Available from: http://cscmp.org/aboutus/supply-chain-management-definitions.

10. Sarkis, J., A strategic decision framework for green supply chain management. Journal of Cleaner Production, 2003. 11(4): p. 397-409.

11. Hervani, A., M.M. Helms, and J. Sarkis, Performance measurement for green supply chain management. Benchmarking: An International Journal, 2005. 12(4): p. 330 - 353.

12. Anker-Rasch, T.-L. and S.D. Sørgard, Green Supply Chain Management. 2011.

13. Srivastava, S.K., Green supply-chain management: $A$ state-of-the-art literature review. International Journal of Management Reviews, 2007. 9(1): p. 53-80.

14. Stevens, C., Measuring Sustainable Development, in STATISTICS BRIEF, O.f.E.C.-o.a. Development, Editor. 2005, OECD.

15. Veleva, V., et al., Indicators of sustainable production. Journal of Cleaner Production, 2001. 9(5): p. 447-452.

16. Morash, E.A., Supply Chain Strategies, Capabilities, and Performance. Transportation Journal, 2001. 41(1): p. 37.

17. Perez-Franco, R.J., A Methodology to Capture, Evaluate and Reformulate a Firm's Supply Chain Strategy as a Conceptual System, in Engineering Systems Division. 2010, Massachusetts Institute of Technology.

18. Cohen, S. and J. Roussel, Strategic Supply Chain Management - The five disciplines for top performance. 2005. 
Author

19. Seuring, S. and M. Müller, From a literature review to a conceptual framework for sustainable supply chain management. Journal of Cleaner Production, 2008. 16(15): p. 1699-1710.

20. Council, S.-S.C. Supply Chain Operations Reference (SCOR®) model Overview - Version 10.0. 2010.

21. Sobotka, M. and K. Platts, Managing without measuring: a study of an electricity distribution company. Measuring business excellence, 2010. 14(1): p. 28-42.

22. Funk, K., Sustainability and performance. MIT Sloan Management Review, 2003. 44(2): p. 65-70.

23. Hutchins, M.J., Framework, indicators, and techniques to support decision making related to societal sustainability, J.W.G.J.S. Sutherland, Editor. 2010, Mechanical Engineering-Engineering Mechanics: United States -- Michigan.

24. Parmenter, D., Key Performance Indicators: Developing, Implementing, and Using Winning KPls. 2009: p. 320.

25. Link, P. and C. Marxt, Integration of risk-and chance management in the co-operation process. International Journal of Production Economics, 2004. 90(1): p. 71-78.

26. Jallow, A.K., et al., Operational risk analysis in business processes. Bt Technology Journal, 2007. 25(1): p. 168-177.

27. Suh, B. and I. Han, The IS risk analysis based on a business model. Information \& Management, 2003. 41(2): p. 149-158.

28. Kaplan, R.S. and D.P. Norton, Transforming the balanced scorecard from performance measurement to strategic management: Part $I$. Accounting horizons, 2001. 15(1): p. 87-104.

29. Forrester, J.W., System dynamics, systems thinking, and soft OR. System Dynamics Review, 1994. 10(2-3): p. 245-256.

30. Mamdani, E.H., Application of fuzzy logic to approximate reasoning using linguistic synthesis. Computers, IEEE Transactions on, 1977. 100(12): p. 1182-1191.

31. Cordón, O., A historical review of evolutionary learning methods for Mamdani-type fuzzy rule-based systems: Designing interpretable genetic fuzzy systems. International Journal of Approximate Reasoning, 2011. 52(6): p. 894-913.

32. Charnes, A., Data envelopment analysis: theory, methodology and applications. 1994: Springer. 